\title{
A Detailed and High-Resolution Land Use and Land Cover Change Analysis over the Past 16 Years in the Horqin Sandy Land, Inner Mongolia
}

\author{
Xiulian Bai, ${ }^{1}$ Ram C. Sharma, ${ }^{2,3}$ Ryutaro Tateishi, ${ }^{2}$ Akihiko Kondoh, \\ Bayaer Wuliangha, ${ }^{4}$ and Gegen Tana ${ }^{2}$ \\ ${ }^{1}$ Graduate School of Science, Chiba University, 1-33 Yayoi-cho, Inage-ku, Chiba 263-8522, Japan \\ ${ }^{2}$ Center for Environmental Remote Sensing (CEReS), Chiba University, 1-33 Yayoi-cho, Inage-ku, Chiba 263-8522, Japan \\ ${ }^{3}$ Department of Informatics, Tokyo University of Information Sciences, 4-1 Onaridai, Wakaba-ku, Chiba 265-8501, Japan \\ ${ }^{4}$ College of Geographical Science, Inner Mongolia Normal University, Hohhot 010022, China \\ Correspondence should be addressed to Xiulian Bai; baixiulian@163.com
}

Received 13 October 2016; Revised 9 December 2016; Accepted 26 December 2016; Published 31 January 2017

Academic Editor: Hasi Bagan

Copyright (C) 2017 Xiulian Bai et al. This is an open access article distributed under the Creative Commons Attribution License, which permits unrestricted use, distribution, and reproduction in any medium, provided the original work is properly cited.

\begin{abstract}
Land use and land cover (LULC) change plays a key role in the process of land degradation and desertification in the Horqin Sandy Land, Inner Mongolia. This research presents a detailed and high-resolution $(30 \mathrm{~m})$ LULC change analysis over the past 16 years in Ongniud Banner, western part of the Horqin Sandy Land. The LULC classification was performed by combining multiple features calculated from the Landsat Archive products using the Support Vector Machine (SVM) based supervised classification approach. LULC maps with 17 secondary classes were produced for the year of 2000, 2009, and 2015 in the study area. The results showed that the multifeatures combination approach is crucial for improving the accuracy of the secondary-level LULC classification. The LULC change analyses over three different periods, 2000-2009, 2009-2015, and 2000-2015, identified significant changes as well as different trends of the secondary-level LULC in study area. Over the past 16 years, irrigated farming lands and salinized areas were expanded, whereas the waterbodies and sandy lands decreased. This implies increasing demand of water and indicates that the conservation of water resources is crucial for protecting the sensitive ecological zones in the Horqin Sandy Land.
\end{abstract}

\section{Introduction}

Desertification is one of the crucial environmental issues that restrict the social, economic, and political development in arid and semiarid area $[1,2]$. Desertification has been defined in several ways; however, the most widely accepted one has defined the desertification as the land degradation in arid, semiarid, and dry subhumid areas resulting from various factors, including climate variations and human activities [36]. In recent years, many socioenvironmental problems such as land shortage, environmental deterioration, reduction of biological and economic productivity, water scarcity, poverty, and migrations have emerged due to rapid spread of the desertification. These problems have threatened the human survival and sustainable economic development [7-9]. It is argued that sustainability will be a great challenge of the human society in coming decades particularly in the transitional and marginal agricultural zones [10-12].

China is a developing country with large population and scarce arable land, which is plagued by a long-term and large-scale desertification [13]. In China, desertified areas are mostly distributed in the western part of the northeast China, the north part of the northern China, and most parts of the northwest China $[14,15]$. The desert areas in China are still expanding by $2460-10,400 \mathrm{~km}^{2}$ per year. As much as 3.317 million $\mathrm{km}^{2}$ ( $34.6 \%$ of the total land area) land area in China is affected by the desertification; and up to 400 million people are struggling with unproductive 
agricultural land and water shortages [14]. The government of China and social media have focused on the desertification problems [15]. The government has implemented a series of ecological engineering programs to combat the desertification, including the Three-North Shelter Forest Program from 1978, Beijing and Tianjin Sandstorm Source Treatment Program from 2001 to 2010, Grain to Green Program from 2003, and Returning Grazing Land to Grassland Program from 2003 [13]. However, monitoring and assessment of these programs have identified very limited success in a few local regions [16-20], while desertification is increasing further in some desertification areas.

The Horqin Sandy Land, one of the four largest sandy land in the northern China, has a long history of desertification and land degradation. Rapid increase in population and inappropriate human activities such as agricultural reclamation, overgrazing, excessive collection of fuel wood and herbs, unmanaged tourism, overconsumption of water resource, and mining and road cutting have induced the desertification continuously in the Horqin Sandy Land [18, 21, 22]. Moreover, climate change in the recent decades has severely intensified the desertification [23]. During Liao Dynasty (907-1125 AD), the Horqin Sandy Land was full of tall forests and dense grasslands which used to sustain nomadic herders [13]. Since the nineteenth century, rapid increase of agriculturalist migrants into this region started to convert the ancient grassland and woodland into agricultural areas which reduced the available grazing land and put the marginal lands under cultivation. This situation continued to twentieth century and reached the peak of development in the 1950s-1960s, with rapid expansion of the human settlements and urban areas [24]. In the beginning of the Great Leap Forward (1958-1960) and during the following two decades, expanding cultivation led to forcing the local nomadic herders to moving into the border area, and most of the area was occupied by agriculturalists $[25,26]$. By the early 1980 s, the rural reform program under the "household responsibility" system played a key role in the overgrazing of grassland; and now the implementation of "double responsibility" system by the local government may do little to reduce the overgrazing [24]. With the development in the agricultural and industrial sectors, these essentially uncontrolled activities have resulted in the destruction of woodland and grassland, degradation of surface soil, and increased water consumption [24].

Accurate land use and land cover (LULC) maps derived from the remote sensing data are highly important for the monitoring and quantification of the global environment as well as spatiotemporal changes [27]. The LULC change analysis assists decision-makers to understand the dynamics of changing environment and can ensure the sustainable development [28]. Multitemporal and multiscale remote sensing can provide substantial information about the land surface and facilitate the monitoring of environmental problems such as land degradation [29]. The combination of spectral, textural, and topographic features has been suggested for improving the accuracy of LULC mapping while producing the recent nationwide $30 \mathrm{~m}$ resolution LULC map of Japan [30]. Since the previous studies in the Horqin Sandy Land have focused on mapping of the LULC and spatial-temporal change analysis mainly based on the spectral information from the satellite data [31], accuracy of the resulting change information is a major concern that is immensely important for the decision-makers.

The availability of the high spatial resolution and multitemporal satellite imagery from the archived Landsat datasets provides a unique opportunity for the monitoring of land degradation and desertification. This study deploys the archived Landsat datasets of years 2000, 2009, and 2015 for deriving the high-resolution LULC change information to present detailed LULC change pattern. Since 2000, the state and local government implements a series of ecological restoration projects to mitigate the further desertification and restoration of desertified grassland in the fragile environment of the Horqin Sandy Land [13]. The main objective of this study is to analyze the spatiotemporal pattern of the LULC changes in the Horqin Sandy Land. This study presents the improvement of the LULC classification accuracy by combining the multiple features (spectral features, spectral indices, spectral transformations, and textural and topographic features) derived from the satellite data using the Support Vector Machine (SVM) based supervised classification approach. While the previous studies in the Horqin Sandy Land have analyzed the LULC changes using major land cover types only [11], this study has achieved the more detailed LULC change information by adding the secondary classes. The analysis on the spatiotemporal change pattern is expected to reveal the mechanisms responsible for the desertification processes.

\section{Materials and Methods}

2.1. Study Area. This study was carried out in Ongniud Banner, in the western part of the Horqin Sandy Land in Inner Mongolia, China. The Ongniud Banner belongs to the transitional zone of the agricultural and animal husbandry region, which is vulnerable ecological region to natural changes and anthropogenic activities [32]. This region is severely suffering from soil erosion and overconsumption and overexploiting of land resources [32, 33]. The location map of the study area is shown in Figure 1. The study area covers an area of $11,882 \mathrm{~km}^{2}$, which stretches $250 \mathrm{~km}$ from east to west and $84 \mathrm{~km}$ from north to south.

The three typical geomorphological characteristics throughout the study area are from west to east in the order of high elevation alluvial flats, low mountains and hills, and low Aeolian dunes, and the altitude decreases from $2025 \mathrm{~m}$ in the west to $286 \mathrm{~m}$ in the east [33]. The climate of this region is characterized by temperate semiarid with windy and dry winters/springs, warm and relatively rainy summers, and cool autumns. The mean annual temperature is $7^{\circ} \mathrm{C}$; annual mean precipitation is $300 \mathrm{~mm}$, of which $70 \%$ precipitation falls between July and September. The mean annual wind velocity is $4.2 \mathrm{~m} \mathrm{~s}^{-1}$ [34]; the windy season lasts from early March to late May. As the study area is comprised of the mosaic of farmland, grassland, and steppe desert with different soil types and land cover forms, this study area offers an opportunity to assess the performance 


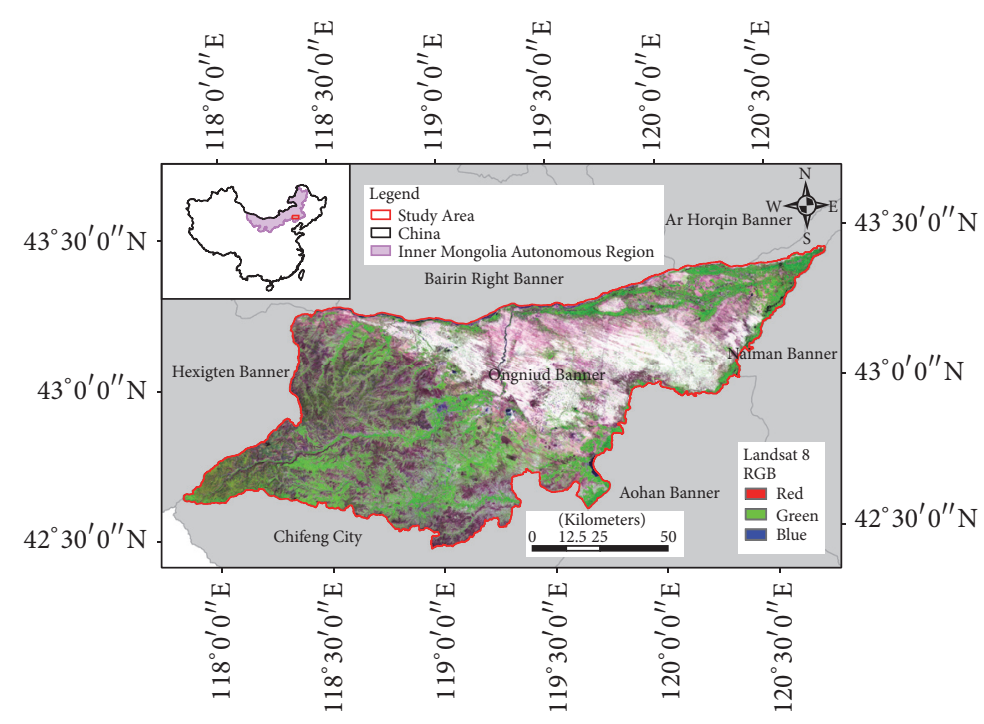

FIGURE 1: Location map of the study area (red polygon) displayed over the Landsat 8 data based false color composite (FCC) image.

of remote sensing data for change analysis of the detailed, secondary-level classes.

2.2. Datasets and Preprocessing. In this research, the Landsat 5 Thematic Mapper (TM) datasets of years 2000 and 2009 and Landsat 8 Operational Land Imager/Thermal Infrared Sensor (OLI/TIRS) datasets of year 2015 available from the United States Geological Survey (USGS) were used. The details on the Landsat datasets used in the research are shown in Table 1. All the $30 \mathrm{~m}$ resolution Landsat scenes used in the research were carefully selected from the highest vegetation activity period between July and September; and they were without cloud cover. In addition to the Landsat 5 and Landsat 8 datasets, $30 \mathrm{~m}$ resolution Shuttle Radar Topography Mission (SRTM) based Digital Elevation Model (DEM) data available from the United States Geological Survey (USGS) was used.

The land use dataset of Inner Mongolia at 1:10,0000 of years 1995 and 2000, desert distribution dataset of China at $1: 10,0000$, vegetation map of China at $1: 400,0000$, and China soil database available from the Chinese Academy of Sciences were used as the reference datasets [12]. Due to different created time and lower resolution of data, it was just used to grasp broader view of the LULC types in the study area. In addition, very high-resolution $(2.5 \mathrm{~m})$ SPOT5 mosaic image of year 2009, Google Earth based images, and local knowledge were mainly used for reference data to training data collection and validation of secondary-level LULC classes. The preprocessing of the Landsat data involves calculation of the top of atmosphere reflectance (TOA), ground control points (GCPs) based coregistration of the multitemporal images, mosaicking, and final subsetting of the data over the study area.

2.3. Classification Scheme and Training Data. Collection of the highly representative training data is a crucial task for the supervised classification of the LULC. In the research, following with the land cover classification system defined by the Chinese Academy of Sciences through field survey, training data belonging to 17 secondary classes were collected for each of these years (2000, 2009, and 2015). Existing land use and vegetation maps, false color composite images prepared from Landsat 5 and Landsat 8 data, Google Earth images, and Spot-5 images were used as the reference datasets while collecting the training and validation data. The classification scheme used in the research and the number of training data (polygons/pixels) collected are listed in Table 2.

To enhance the comparability of land cover classification results during three periods, we used the same training sites as much as possible when no change occurred. The pixelbase region of interest polygons was not a constant grid size but varied with the size and shape of the feature of interest. This variation was in order to take into account the areal distribution of various land cove features and to avoid oversampling one land cove type. The reliability of the training data over the entire study area was further ensured by using Jeffries-Matusita (J-M) distance [35]. The J-M distance algorithm used to calculate the separability of two land cover classes according to the following algorithm:

$$
\operatorname{JM}_{(i, j)}=2\left[1-e^{\left(-a_{(i, j)}\right)}\right],
$$

where $\mathrm{JM}_{(i, j)}$ indicate Jeffries-Matusita distance between classes $i$ and $j$ and $a_{(i, j)}$ is shown as follows:

$$
\begin{aligned}
a_{(i, j)}= & 0.125\left[M_{(i)}-M_{(j)}\right] \ln V\left[A_{(i, j)}\right]\left[M_{(i)}-M_{(j)}\right] \\
& +0.5 \ln \left\{\frac{\left(\operatorname{det}\left(A_{(i, j)}\right)\right)}{\left(\operatorname{det}\left(S_{(i)} \times \operatorname{det}\left(S_{(j)}\right)\right)\right)}\right\}^{1 / 2},
\end{aligned}
$$

where $M$ indicate mean vector and $S$ indicate covariance matrix.

$\mathrm{J}$-M distance value ranges from 0 to 2; if $\mathrm{J}-\mathrm{M}$ distance value close to 2 indicates training data of two land types with 
TABLE 1: Description of the Landsat scenes used in the research.

\begin{tabular}{lcccc}
\hline Datasets & Path/row & Date acquired & Spatial resolution & Data source \\
\hline & $121 / 30$ & 30 August 2000 & Bands 1-5 and 7 with & United States Geological Survey \\
Landsat 5 TM & $122 / 30$ & 6 September 2000 & 30 m; & (USGS) (http://glovis.usgs.gov/) \\
& $121 / 30$ & 23 August 2009 & Bands 6 with $120 \mathrm{~m}$ & http://glovis.usgs.gov/ \\
& $122 / 30$ & 15 September 2009 & & \\
\hline & $121 / 30$ & 7 July 2015 & Bands 1-7 with 30 m; & Bands 10 and 11 with \\
\hline
\end{tabular}

TABLE 2: LULC classification system and the number of training data (polygons/pixels) used in the research.

\begin{tabular}{|c|c|c|c|c|}
\hline \multirow{2}{*}{ First level classes } & \multirow{2}{*}{ Second level classes } & \multicolumn{3}{|c|}{ Training data: number of polygons (pixels) } \\
\hline & & 2000 & 2009 & 2015 \\
\hline \multirow{3}{*}{ Cropland } & Paddy & $18(3641)$ & $21(2969)$ & $17(3684)$ \\
\hline & Dry land & $43(7489)$ & $57(9793)$ & $64(10792)$ \\
\hline & Irrigation land & $35(3919)$ & $51(4643)$ & $57(7686)$ \\
\hline \multirow{3}{*}{ Woodland } & Forest & $50(4113)$ & $39(4347)$ & $52(7150)$ \\
\hline & Shrub & $29(2852)$ & $30(8171)$ & $27(6396)$ \\
\hline & Other forests & $26(4194)$ & $27(3969)$ & $31(5370)$ \\
\hline \multirow{3}{*}{ Grassland } & Dense grass & $34(5085)$ & $31(3573)$ & $29(5936)$ \\
\hline & Moderate grass & $32(3005)$ & $32(3005)$ & $26(5933)$ \\
\hline & Sparse grass & $33(2369)$ & $34(2671)$ & $35(8244)$ \\
\hline \multirow{2}{*}{ Water body } & Rivers and lakes & $24(5379)$ & $18(4682)$ & $21(6118)$ \\
\hline & Tidal & $20(1181)$ & $19(1340)$ & $25(1835)$ \\
\hline \multirow{2}{*}{ Built-up land } & Urban built-up & $15(1877)$ & $10(3312)$ & $10(4385)$ \\
\hline & Rural settlements & $40(3846)$ & $37(3527)$ & $40(4548)$ \\
\hline \multirow{4}{*}{ Unused land } & Sandy land & $31(7993)$ & $31(9423)$ & 46 (16651) \\
\hline & Salina & $22(3121)$ & $22(3121)$ & 19 (2913) \\
\hline & Swampland & $11(1588)$ & $9(560)$ & $5(742)$ \\
\hline & Bare & 43 (1837) & $50(3283)$ & 37 (3909) \\
\hline
\end{tabular}

a high degree of separability, then those values close to 0 indicate a low degree of separability.

\subsection{Multifeatures Combination and Supervised Classification.} The study area is mix of the diverse types of LULC. Considering the spectral complexity of the study area, combination of the multiple features (spectral features, spectral indices, spectral transformations, textures, and topographic features) calculated from the satellite data was used to improve the accuracy of the LULC classification. The list of spectral features used in the research is shown in Table 3. Altogether, 25 feature images were used as an input dataset in the research. These features were calculated separately for each of these years $(2000,2009$, and 2015) using the satellite data of the corresponding year.

The six spectral bands of the Landsat data were used for the principal component analysis, and the first principal component which included more than $90 \%$ spectral information was used to calculate textural features. Eight textural measures (mean, variance, homogeneity, contrast, dissimilarity, entropy, second moment, and correlation) were calculated using the Gray Level Cooccurrence Matrix (GLCM) with the moving window size of 3 by 3 pixels.

LULC classification and mapping were conducted for each of these years $(2000,2009$, and 2015) using the abovementioned 25 feature images and the training data collected. The supervised classification was conducted using the Support Vector Machine (SVM) [36] algorithm. SVM is a nonparametric classification method which can also work with the small amount of training data and produce higher classification accuracy [37, 38].

The success of the SVM method depends on how well the process is trained. Principally, SVM is a binary classifier that set an optimal separating hyperplane during classes to correctly separate the data point into two classes [39]. If the training data with $k$ number of samples are represented as $\left(x_{1}, y_{1}\right), \ldots,\left(x_{k}, y_{k}\right)$ where $x \in R^{n}$ is an $n$-dimensional space and $y \in\{+1,-1\}$ is class label, then these training data will be separated by the two hyperplanes parallel to the optimal 
TABLE 3: List of feature images used in the research.

\begin{tabular}{|c|c|c|}
\hline Features & Descriptions & Total \\
\hline Spectral & $\begin{array}{l}\text { Blue, green, red, near infrared, shortwave infrared, and } \\
\text { thermal infrared }\end{array}$ & 6 \\
\hline Spectral indices & $\begin{array}{l}\text { Normalized difference vegetation index (NDVI), normalized } \\
\text { difference built-up index (NDBI), normalized difference } \\
\text { bareness index (NDBaI), normalized difference salinity index } \\
\text { (NDSI), normalized difference water index (NDWI) }\end{array}$ & 5 \\
\hline $\begin{array}{l}\text { Spectral } \\
\text { transformations }\end{array}$ & $\begin{array}{l}\text { Tasseled cap-wetness, tasseled cap-greenness, tasseled } \\
\text { cap-brightness }\end{array}$ & 3 \\
\hline Textural & $\begin{array}{l}\text { Mean, variance, homogeneity, contrast, dissimilarity, entropy, } \\
\text { second moment, correlation }\end{array}$ & 8 \\
\hline Topographic & Slope, altitude, aspect & 3 \\
\hline Total & & 25 \\
\hline
\end{tabular}

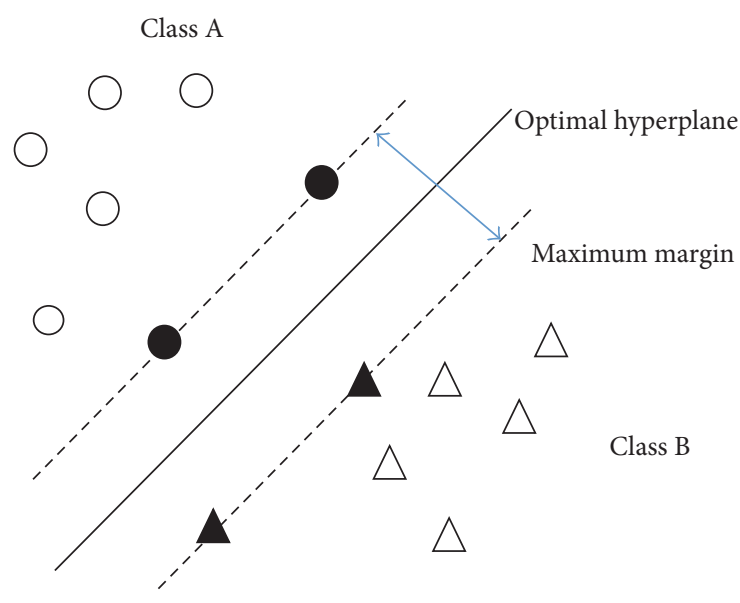

Figure 2: Original idea of SVM.

hyperplane with maximum margin into the respective classes shown in

$$
\begin{array}{ll}
W \cdot x_{i}+b \geq+1 & \text { for } y_{i}=+1, i=1,2, \ldots, k \\
W \cdot x_{i}+b \leq-1 & \text { for } y_{i}=-1 .
\end{array}
$$

The original idea of SVM is presented in Figure 2.

SVM can classify the data linearly and nonlinearly, and kernel function is used for nonlinear classification. The SVM provide four types of kernels: linear, polynomial, and radial basis function (RBF), and sigmoid. According to the previous studies, radial basis function kernel works better for remote sensing image classification [40]. The equation of radial basis function kernel is presented as follows:

$$
K\left(x_{i}, x_{j}\right)=\exp \left(-g\left\|x_{i}-x_{j}\right\|^{2}\right), \quad g>0,
$$

where $g$ indicate the gamma term in the radial basis kernel function. This study utilized the default parameter provided by ENVI software to perform supervised classification on Landsat images.
2.5. Change Analysis and Accuracy Assessment. Accuracy of the LULC classification was assessed by collecting the different sets of validation data. The collection procedure was similar to the training data, but the training data used for training the SVM model were not used for assessing the classification accuracy. Altogether, 50 pixels for each secondary class were randomly chosen from the classified image, and the corresponding geolocation points were confirmed by visual interpretation of the reference datasets. The overall accuracy and kappa coefficient were used as the metrics for assessing the classification accuracy. After the production of LULC maps of each of these years (2000, 2009, and 2015) in the study area and their validation, the postclassification comparison (PCC) technique was used for the derivation of LULC change information. The spatiotemporal change analysis of 17 secondary classes is presented in the research.

\section{Results and Discussion}

3.1. LULC Classification Results. The LULC classification maps of years 2000, 2009, and 2015 produced in the research are displayed in Figures 3, 4, and 5, respectively. Each of these maps includes 17 secondary classes in the study area.

The areal coverage and proportion of 17 LULC secondary classes for each year $(2000,2009$, and 2015) are presented in Figure 6 and Table 4.

The main LULC classes of the study area in the year 2015 were found to be grassland (dense grass, moderate gras, s and sparse grass), woodland (forest, shrub, and other forests), and cropland (dry farmland, irrigated farmland, and paddy) with the coverage of $39.3 \%, 20.5 \%$, and $19.7 \%$ of the study area, respectively.

3.2. Spatiotemporal Changes. The annual rates of change (\%) of the 17 LULC secondary classes during 2000-2009, 20092015, and 2000-2015 are presented in Table 5.

As shown in Table 5, significant changes in the LULC secondary classes over the past 16 years (2000-2015) have been detected in the study area. Over this period (20002015), dry land, irrigation land, paddy, urban built-up, and rural settlement were expanded with an annual rate of $1.11 \%$, $4.07 \%, 1.57 \%$, and $2.00 \%$, respectively, in which irrigation 


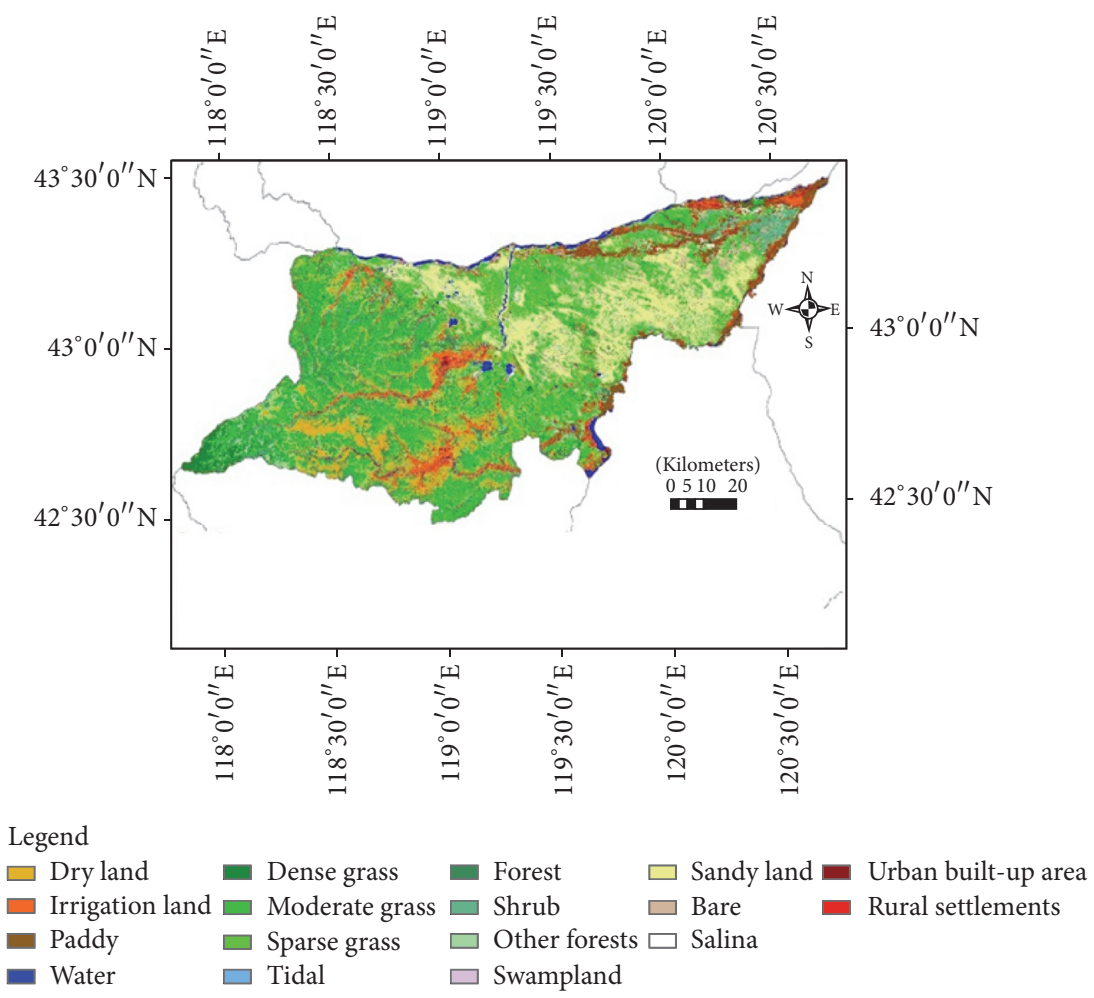

FigURE 3: LULC classification map of year 2000 in the study area.

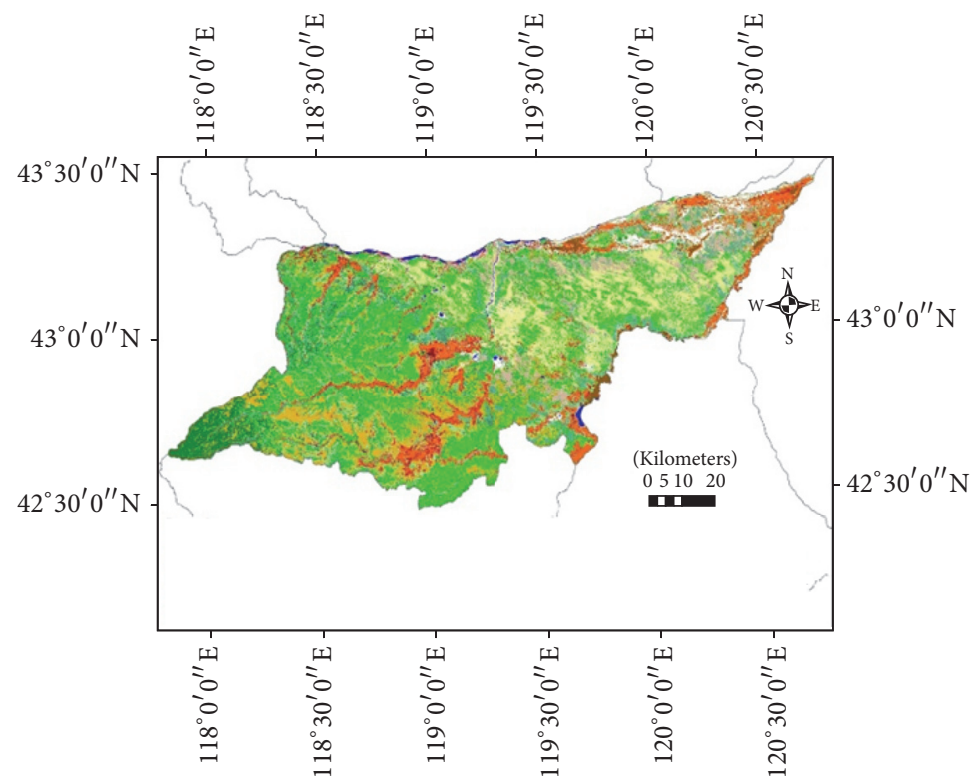

\footnotetext{
Legend

$\square$ Dry land

Dense grass Forest

$\square$ Irrigation land $\square$ Moderate grass $\square$ Shrub

$\square$ Sandy land $\square$ Urban built-up area

- Paddy

$\square$ Sparse grass

Shrub $\square$ Bare

Rural settlements

- Water

$\square$ Tidal

$\square$ Swampland
}

FIgURE 4: LULC classification map of year 2009 in the study area. 


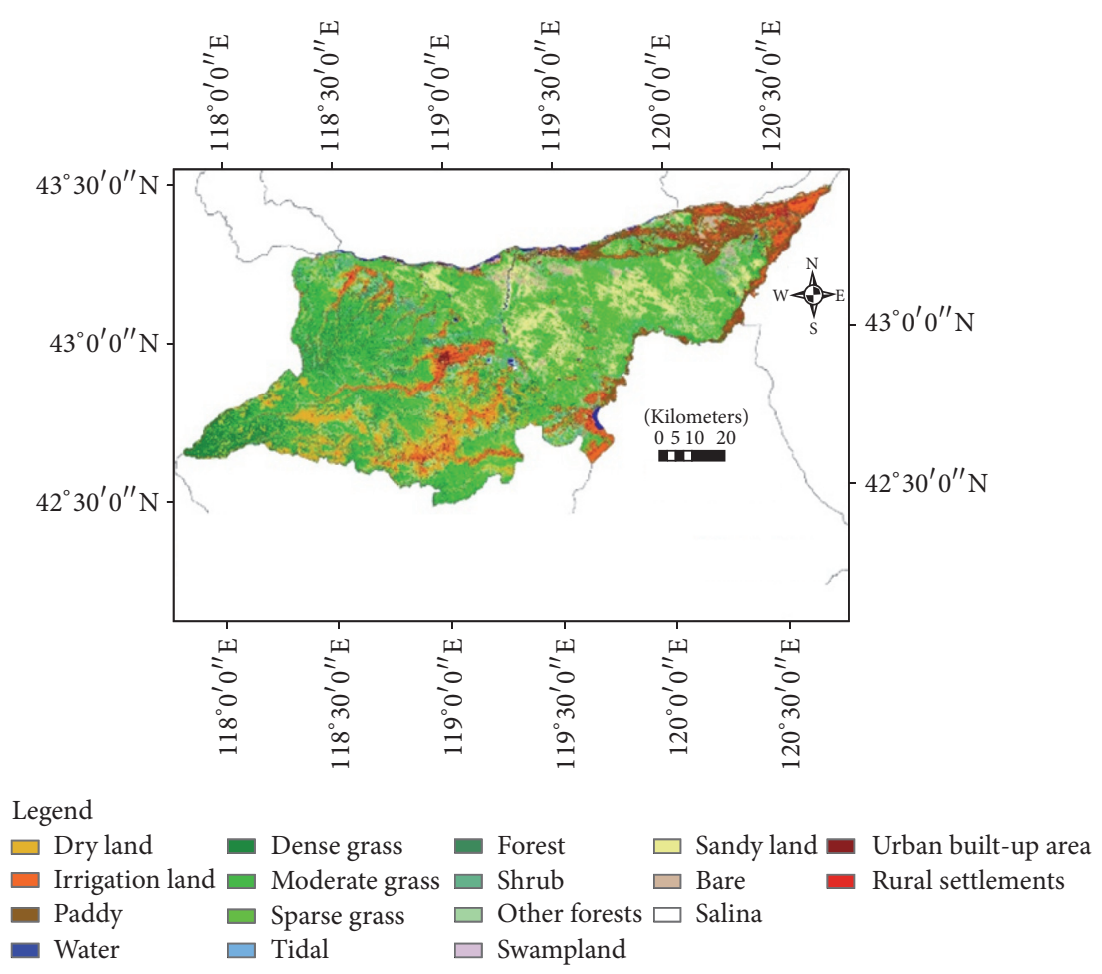

FIGURE 5: LULC classification map of year 2015 in the study area.

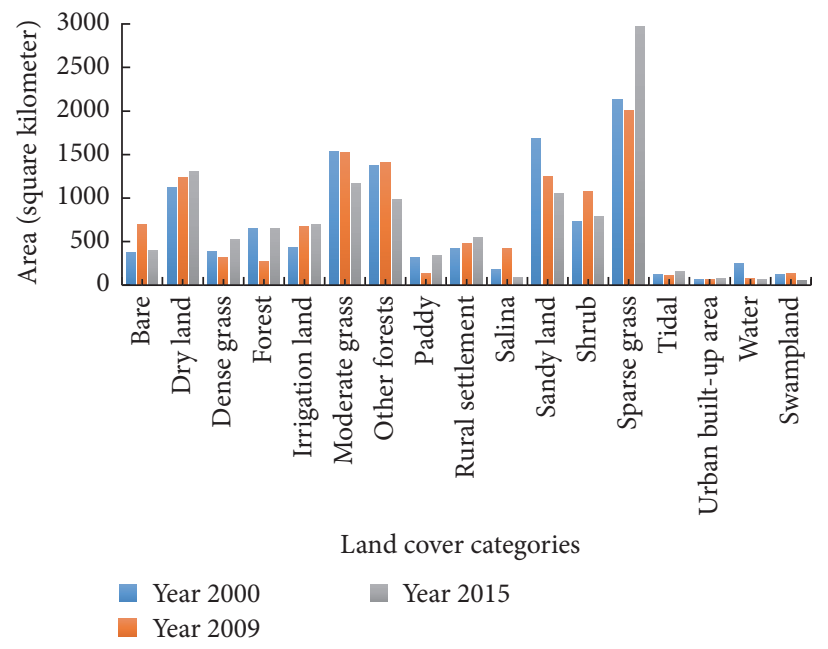

FIgURE 6: Areal coverage of the 17 LULC secondary classes of years 2000, 2009, and 2015 in the study area.

land is expanding most fast. However, at the same period (2000-2015), water, swampland, sandy land, and moderate grass were reduced at an annual rate of $4.87 \%, 3.74 \%, 2.51 \%$, and $1.59 \%$, respectively.

The fluctuation trend of the LULC classes was also detected in the study area. During the period 2000-2009, bare, salina, and shrub expanded significantly (positive annual changes) with an annual rate of $9.65 \%, 15.51 \%$, and $5.33 \%$; however, they decreased (negative annual changes) in the next 6 years (2009-2015). On the other hand, dense grass, forest, paddy, sparse grass, and tidal decreased between 2000 and 2009; however, these classes expanded during 2009-2015.

The most evident spatial-temporal changes of the water bodies, irrigation lands, sandy lands, and salina (salinized lands) found over the period of 2000-2015 in the research are demonstrated in Figures 7-10, respectively.

The Ongniud Banner region located in the western part of the Horqin Sandy Land is a typical transition zone of agricultural and animal husbandry. Over the past five decades, this region has been affected by land degradation 


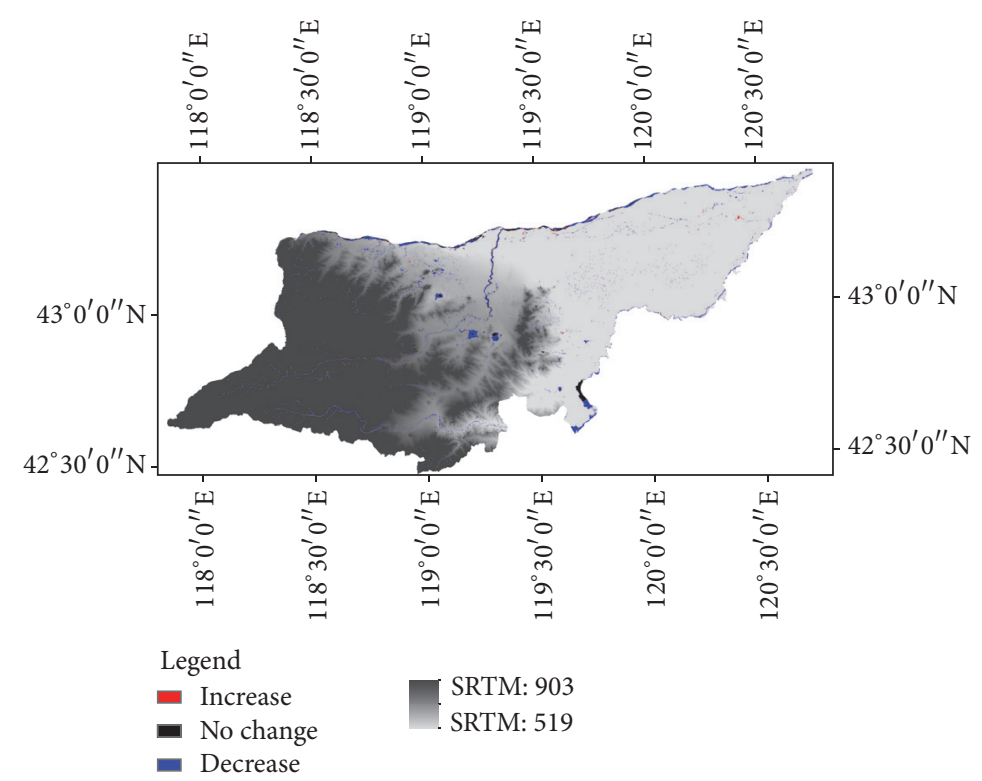

FIGURE 7: Changes in water bodies between 2000 and 2015 in the study area.

TABLE 4: The areal coverage and proportion of the 17 LULC secondary classes of years 2000, 2009, and 2015 in the study area.

\begin{tabular}{|c|c|c|c|c|c|c|}
\hline \multirow{2}{*}{ LULC types } & \multicolumn{3}{|c|}{ Area (square kilometers) } & \multicolumn{3}{|c|}{ Proportion (\%) } \\
\hline & 2000 & 2009 & 2015 & 2000 & 2009 & 2015 \\
\hline Bare & 370.32 & 691.94 & 398.99 & 3.12 & 5.82 & 3.36 \\
\hline Dry land & 1123.82 & 1241.67 & 1310.58 & 9.46 & 10.45 & 11.03 \\
\hline Dense grass & 390.56 & 321.36 & 526.04 & 3.29 & 2.70 & 4.43 \\
\hline Forest & 650.07 & 277.11 & 654.82 & 5.47 & 2.33 & 5.51 \\
\hline Irrigation land & 430.31 & 674.35 & 693.33 & 3.62 & 5.67 & 5.83 \\
\hline Moderate grass & 1537.22 & 1520.58 & 1169.51 & 12.93 & 12.79 & 9.84 \\
\hline Other forest & 1370.81 & 1407.63 & 989.34 & 11.53 & 11.84 & 8.32 \\
\hline Paddy & 313.58 & 138.46 & 341.18 & 2.64 & 1.16 & 2.87 \\
\hline Rural settlement & 421.63 & 477.35 & 548.19 & 3.55 & 4.02 & 4.61 \\
\hline Salina & 175.09 & 419.46 & 85.02 & 1.47 & 3.53 & 0.72 \\
\hline Sandy land & 1684.27 & 1245.83 & 1051.09 & 14.17 & 10.48 & 8.84 \\
\hline Shrub & 728.48 & 1078.00 & 790.45 & 6.13 & 9.07 & 6.65 \\
\hline Sparse grass & 2135.63 & 2001.15 & 2971.38 & 17.97 & 16.84 & 25.00 \\
\hline Tidal & 124.93 & 108.95 & 162.29 & 1.05 & 0.92 & 1.37 \\
\hline Urban built-up area & 60.22 & 67.63 & 74.36 & 0.51 & 0.57 & 0.63 \\
\hline Water & 250.60 & 76.84 & 67.47 & 2.11 & 0.65 & 0.57 \\
\hline Swampland & 118.35 & 137.56 & 51.87 & 1.00 & 1.16 & 0.44 \\
\hline Total & 11882 & 11882 & 11882 & 100 & 100 & 100 \\
\hline
\end{tabular}

and desertification due to climate change and irrational human activities [41].

In the arid and semiarid regions, temperature and precipitation are important climatic factors. The analysis of the mean annual temperature and mean annual precipitation in the study area (Figure 11) shows that, between 1998 and 2007, the temperature slightly increased whereas the precipitation decreased significantly, which lead to the dry and hot climate in study area.
Figure 10 exhibited that the minimum annual precipitation occurred in 2001 and 2009 and the study area suffers from severe drought event in year 2009 [47]. According to the detailed analysis result of land cover change from 2000 to 2009 , the increase of the salinized area and bare area between 1998 and 2009 mainly resulted from the dry and hot climate occurred from 1998 to 2007. In particular, less precipitation from 1998 to 2009 plays the key role in the decrease of dense grasses, shrinking swamp land and water body between 2000 


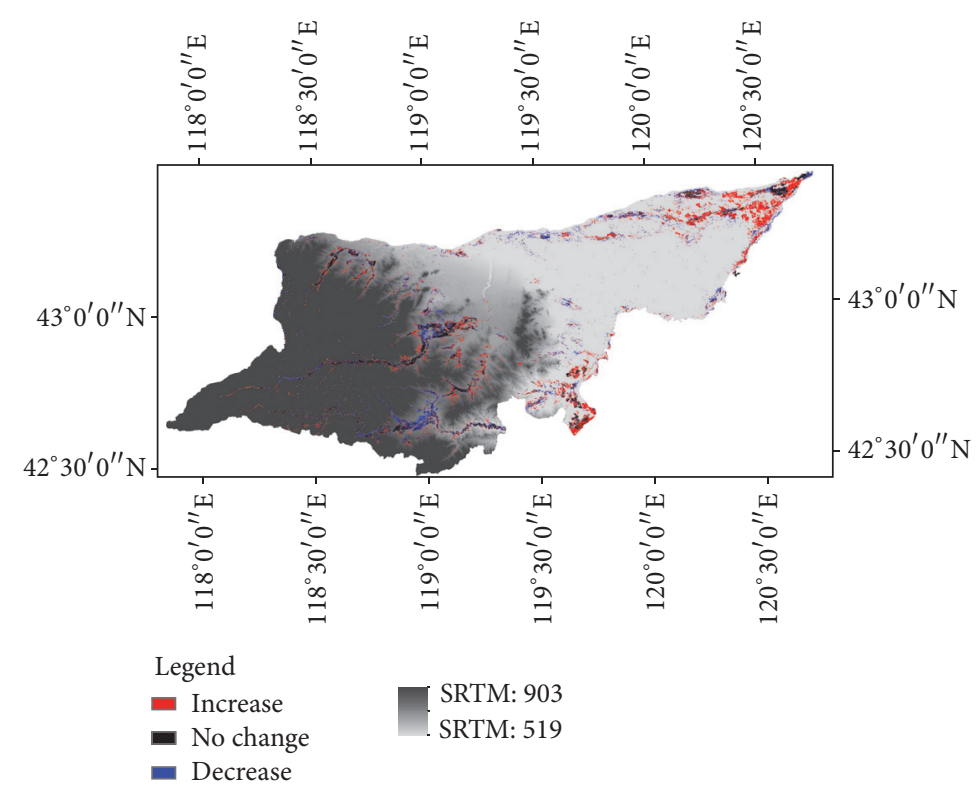

FIgURE 8: Changes in irrigated lands between 2000 and 2015 in the study area.

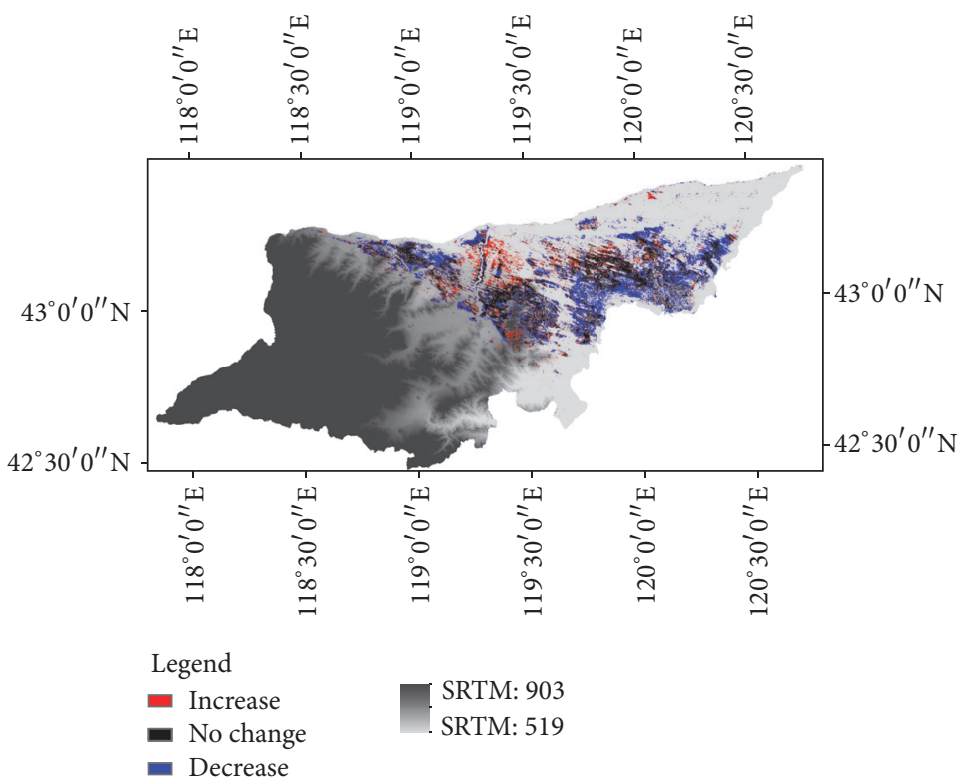

FIGURE 9: Changes in sandy lands between 2000 and 2015 in the study area.

and 2009. On the other hand, the climate variations between 2009 and 2012 exhibited the overall trend with the decrease of annual mean temperature and the increase of annual mean precipitation resulted in increased sparse grasses between 2009 and 2015. The decrease of the precipitation and soil moisture in warm and dry climate restricts the growth of vegetation resulting in exposed soil, shrinkage of water body, and the increase of barren and tidal areas. In contrast, the increase of the precipitation is favorable to the growth of vegetation and biodiversity with high soil moisture and less soil erosion.

The increase of the population and the increase of livestock numbers in the study are two major proxies of anthropogenic causes of the LULC changes in Ongniud Banner region of the Horqin Sandy Land. According to the Inner Mongolia statistical yearbook record, the total population of the Ongniud Banner increased from 463,293 in 2000 to 482,114 in 2014 [42]; and the population density increased from 35.6 persons per $\mathrm{km}^{2}$ in 1986 to 41 persons per $\mathrm{km}^{2}$ in 2014. Similarly, the livestock numbers also increased significantly from 460,000 in 1999 to 1409,300 in 2012. The significant increase of the population and livestock numbers accelerated the demands for water, food, and grazing lands which transformed the natural grasslands and woodlands into cultivated, residential, and degraded areas. As many programs on the protection and restoration of the ecological 


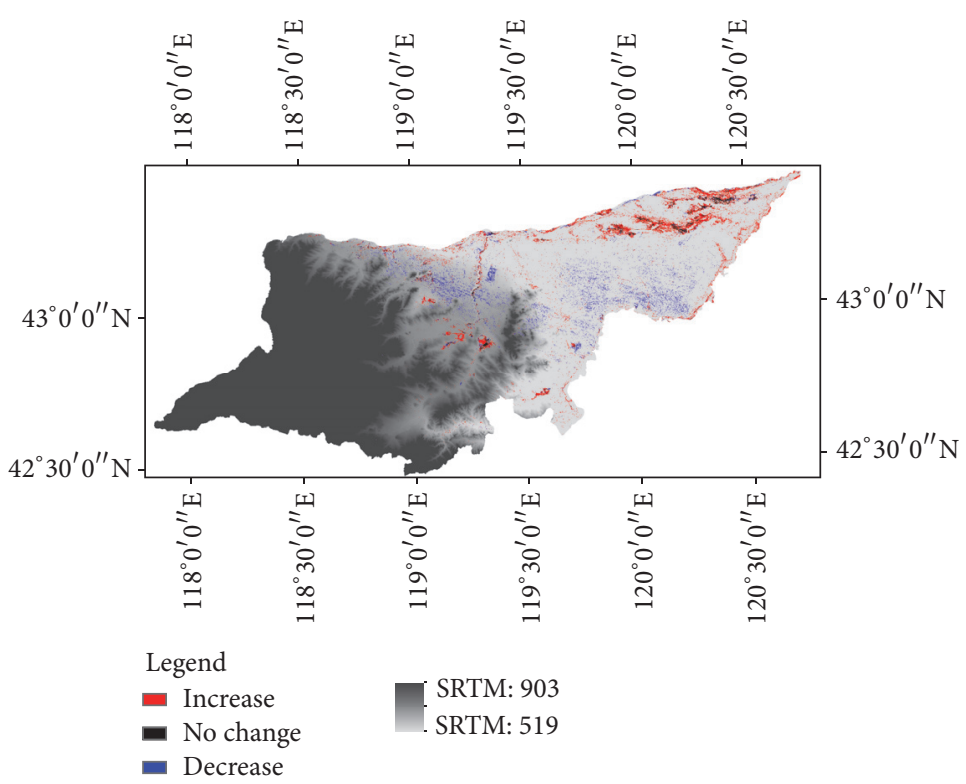

FIGURE 10: Changes in salina between 2000 and 2015 in the study area.

TABLE 5: The annual change rate (\%) of the 17 LULC secondary classes during 2000-2009, 2009-2015, and 2000-2015 in the study area. Positive (negative) value indicates increasing (decreasing) trend over the time period.

\begin{tabular}{lccc}
\hline LULC classes & & Annual rate of change (\%) & $2009-2015$ \\
\hline Bare & $2000-2009$ & -7.06 & 0.92 \\
Dry land & 9.65 & 0.92 & 1.11 \\
Dense grass & 1.17 & 10.62 & 2.31 \\
Forest & -1.97 & 22.72 & 0.05 \\
Irrigation land & -6.37 & 0.47 & 4.07 \\
Moderate grass & 6.30 & -3.85 & -1.59 \\
Other forest & -0.12 & -4.95 & -1.86 \\
Paddy & 0.30 & 24.40 & 0.59 \\
Rural settlement & -6.20 & 2.47 & 2.00 \\
Salina & 1.47 & -13.29 & -3.43 \\
Sandy land & 15.51 & -2.61 & -2.51 \\
Shrub & -2.89 & -4.45 & 0.57 \\
Sparse grass & 5.33 & 8.08 & 2.61 \\
Tidal & -0.70 & 8.16 & 1.99 \\
Urban built-up area & -1.42 & 1.66 & 1.57 \\
Water & 1.37 & -2.03 & -4.87 \\
Swampland & -7.70 & -10.38 & -3.74 \\
\hline
\end{tabular}

zones have been launched by the government, encroachment of the desertification areas should have been controlled. However, expanding agriculture and depletion of groundwater table as reported by previous studies [45] may limit the sustainable development of the region.

3.3. Validation Results. The LULC classification was carried out for each year by accounting for the contribution of each of the additional feature (spectral indices, spectral transformations, textural and topographic features) to the basic Landsat based spectral feature (Landsat 6 bands). The one by one performance of these additional features is shown in Table 6. Based on this analysis, only highly performed features were chosen for the production of the LULC maps. The exclusion of the less contributed features could reduce the data volume for further processing. 
TABLE 6: Contribution of the additional features for the LULC classification in the study area.

\begin{tabular}{ll}
\hline Additional features & Contribution \\
\hline DEM & Improving discrimination among irrigation land, swampland, and paddy \\
Slope & Improving discrimination of grassland and forest and bare area and tidal \\
Aspect & Less contribution \\
NDVI & Improving discrimination between grassland and forest \\
NDWI & Improving discrimination between irrigated land and swampland \\
NDSI & Improving discrimination between salina land and sandy land \\
NDBI & Enhancing discrimination of built-up and rural settlement area \\
NDBaI & Improving discrimination between bare area and salinized area \\
Greenness & Less contribution \\
Brightness & Less contribution \\
Wetness & Less contribution \\
Mean & Improving discrimination between rural settlements and urban built-up area \\
Variance & Less contribution \\
Homogeneity & Improving discrimination between rural settlements and urban built-up area \\
Contrast & Less contribution \\
Dissimilarity & Improving discrimination between cropland and built-up area \\
Entropy & Improving discrimination between artificial grassland and cropland \\
Second moment & Enhancing discrimination of the tidal and rural settlement \\
Correlation & Less contribution \\
\hline
\end{tabular}

TABLE 7: Confusion matrix of the LULC classification for each year in the study area.

\begin{tabular}{|c|c|c|c|c|c|c|}
\hline \multirow{2}{*}{ Classes } & \multicolumn{2}{|c|}{ Year 2000} & \multicolumn{2}{|c|}{ Year 2009} & \multicolumn{2}{|c|}{ Year 2015} \\
\hline & User's accuracy & Producer's accuracy & User's accuracy & Producer's accuracy & User's accuracy & Producer's accuracy \\
\hline Bare & 0.88 & 0.61 & 0.86 & 0.77 & 0.88 & 0.56 \\
\hline Dry land & 0.74 & 0.8 & 0.88 & 0.75 & 0.86 & 0.57 \\
\hline Dense grass & 0.96 & 0.76 & 0.88 & 0.92 & 0.8 & 0.83 \\
\hline Forest & 0.94 & 0.86 & 0.88 & 0.86 & 0.8 & 0.85 \\
\hline Irrigation land & 0.94 & 0.82 & 0.92 & 0.81 & 0.96 & 0.65 \\
\hline Moderate grass & 0.92 & 0.88 & 0.92 & 0.87 & 0.84 & 0.84 \\
\hline Other forests & 0.74 & 0.93 & 0.92 & 0.92 & 0.68 & 0.92 \\
\hline Paddy & 0.88 & 1 & 0.94 & 0.96 & 0.64 & 1 \\
\hline Rural settlements & 0.8 & 0.89 & 0.82 & 0.8 & 0.76 & 0.79 \\
\hline Salina & 0.84 & 0.98 & 0.88 & 0.96 & 0.74 & 0.97 \\
\hline Sandy land & 0.82 & 0.91 & 0.98 & 0.88 & 0.96 & 0.91 \\
\hline Shrub & 0.86 & 0.88 & 0.92 & 0.92 & 0.86 & 0.84 \\
\hline Sparse grass & 0.92 & 0.7 & 0.9 & 0.87 & 0.84 & 0.76 \\
\hline Tidal & 0.86 & 0.93 & 0.82 & 0.89 & 0.82 & 0.91 \\
\hline Urban built-up area & 0.62 & 1 & 0.78 & 1 & 0.76 & 1 \\
\hline Water & 1 & 1 & 0.96 & 1 & 1 & 1 \\
\hline Swampland & 0.84 & 0.93 & 0.86 & 0.98 & 0.78 & 0.98 \\
\hline Overall accuracy & \multicolumn{2}{|r|}{0.86} & \multicolumn{2}{|r|}{0.89} & \multicolumn{2}{|r|}{0.82} \\
\hline Kappa coefficient & \multicolumn{2}{|r|}{0.85} & \multicolumn{2}{|r|}{0.88} & \multicolumn{2}{|r|}{0.81} \\
\hline
\end{tabular}

The performance of the resulting LULC maps assessed through the confusion matrix based analysis using the validation data is shown in Table 7.

The overall accuracy (kappa coefficient) obtained for 17 secondary classes in the study area were $0.86(0.85), 0.89$ (0.88), and 0.82 (0.81) for years 2000, 2009, and 2015, respectively. The classification results of 17 land cover types for 2000 ,
2009, and 2015 were generally reliable. In comparison, the detailed LULC classification map of year 2009 was with a higher overall classification accuracy than both maps of 2000 and 2015. The land cover types, bare, dry land and urban builtup area, are confused with each other with the producer's accuracy for bare being less than 0.7 except in 2009. The producer's accuracy for dry land is less than 0.7 in 2015. 


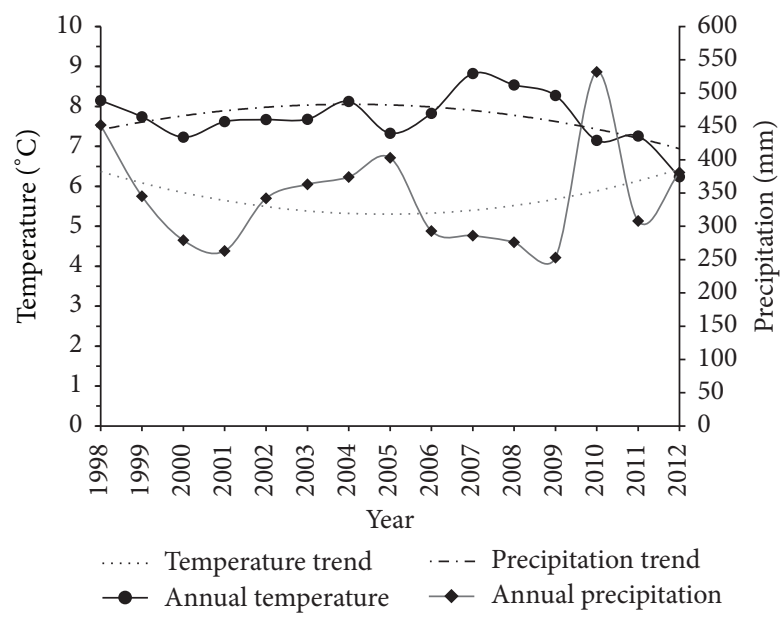

Figure 11: Changes in the annual temperature and annual precipitation in the study area.

The irrigation land is confused with swampland and paddy, with the producer's accuracy being less than 0.7 in Landsat OLI image of 2015. Other classes are considered to be well classified even in Landsat TM and Landsat OLI imagery.

\section{Conclusion}

Previous studies in the Horqin Sandy Land utilized only the spectral feature from the satellite data for the change analysis of major LULC classes. The analysis of the contribution of each features in the research showed that only the spectral features from the Landsat data are not enough for improving the classification accuracy as the misclassification between the secondary classes such as irrigated land and swampland, swampland and paddy, bare area and tidal, cropland and bare area, bare area and urban, grassland and forest were significant. The additional features (spectral indices, spectral transformations, and textural and topographic features) could improve the classification accuracy significantly.

The secondary class level LULC change analysis performed in the research provides very detailed change information of the LULC over the past 16 years. The high resolution $(30 \mathrm{~m})$ LULC change analysis over the past 16 years in the research showed a significant LULC change in Ongniud Banner, western part of the Horqin Sandy Land in Inner Mongolia. Different trends of the LULC changes over three periods, 2000-2009, 2009-2015, and 2000-2015, were also detected. Interaction of the human activities and the climatic factors (precipitation and temperature) could be linked to the trend of LULC changes.

The satellite remote sensing based detailed LULC change analysis as performed in the study is important for assessing the performance of the ecological protection and restoration programs. The spatiotemporal change analyses of the detailed secondary classes in the research are expected to contribute to the policy makers for the protection and sustainable management of the environmentally sensitive ecological resources in the Horqin Sandy Land. This research has confirmed the expansion of irrigated farming lands and salinized areas over the past 16 years, whereas the waterbodies and sandy lands decreased. This trend implies the increasing demand of water resource. Therefore, a continuous and long-term monitoring of the LULC changes related to water resource and salinization problem is suggested to promote sustainable development and ecological security of the northeast China. Based on these research results, rational use of limited water resource and planting water saving vegetation community such as shrub is recommended to the local people. On the other hand, to protect minority land cove types such as swampland, it is challenging to reduce landscape fragmentation and preserve the biodiversity.

\section{Competing Interests}

The authors declare that there are no competing interests regarding the publication of this paper.

\section{References}

[1] A. Warren and C. Agnew, "An assessment of desertification and land degradation in arid and semi-arid areas," International Institute for Environment and Development, Dryland Programme, Dryland Paper 02, Ecology and Conservation Unit, University College, London, UK, 1988.

[2] Y. Chen and H. Tang, "Desertification in north China: background, anthropogenic impacts and failures in combating it," Land Degradation and Development, vol. 16, no. 4, pp. 367-376, 2005.

[3] World Health Organization (WHO), "United Nations Environment Programme (UNEP)," in Urban Air Pollution in Megacities of the World, Blackwell, Cambridge, Mass, USA, 1992.

[4] M. Sciortino, "Desertification in the mediterranean," in Proceedings of the Contributed Paper of the 22th International School on Disarmament and Research on Conflicts (ISODARCO '01), Candriai, Italy, June 2001.

[5] M. B. K. Darkoh, "The nature, causes and consequences of desertification in the drylands of Africa," Land Degradation \& Development, vol. 9, no. 1, pp. 1-20, 1998.

[6] UNCOD and Secretariat, "Desertification: its causes and consequences," in Secretariat of United Nations Conference on Desertification, Pergamon Press, Oxford, UK, 1977.

[7] S.-J. Wang, Q.-M. Liu, and D.-F. Zhang, "Karst rocky desertification in southwestern China: geomorphology, landuse, impact and rehabilitation," Land Degradation \& Development, vol. 15, no. 2, pp. 115-121, 2004.

[8] M. O. H. EI-Karouri, "The impact of desertification on land productivity in Sudan," in Physics of Desertification, pp. 52-58, Springer Netherlands, 1986.

[9] P. Bullock and H. Le Houérou, "Land degradation and desertification," in Climate Change 1995: Impacts, Adaptations and Mitigation of Climate Change: Scientific-Technical Analyses. Contribution of Working Group II to the Second Assessment Report of the Intergovernmental Panel on Climate Change, pp. 171-190, Cambridge University Press, 1996.

[10] R. M. Pink, Water Rights in Southeast Asia and India, Palgrave Macmillan, New York, NY, USA, 2016.

[11] J. Li, B. Xu, X. Yang et al., "Characterizing changes in grassland desertification based on Landsat images of the Ongniud and Naiman Banners, Inner Mongolia," International Journal of Remote Sensing, vol. 36, no. 19-20, pp. 5137-5149, 2015. 
[12] H. Bagan, W. Takeuchi, T. Kinoshita, Y. Bao, and Y. Yamagata, "Land cover classification and change analysis in the Horqin Sandy Land from 1975 to 2007," IEEE Journal of Selected Topics in Applied Earth Observations and Remote Sensing, vol. 3, no. 2, pp. 168-177, 2010.

[13] F. Wang, X. Pan, D. Wang, C. Shen, and Q. Lu, "Combating desertification in China: past, present and future," Land Use Policy, vol. 31, pp. 311-313, 2013.

[14] F. Plit, J. Plit, and W. Żakowski, "Drylands development and combating desertification: bibliographic study of experiences in countries of the CIS," Environment and Energy Paper 14, Food \& Agriculture Organization, 1995.

[15] Jun, "Chinese newspaper report for the issue of desertification of Inner Mongolia," Bulletin of the Graduate School, Toyo University, vol. 49, pp. 25-39, 2012 (Japanese).

[16] F. Huang, P. Wang, and X. Liu, "Monitoring vegetation dynamic in Horqin Sandy Land from SPOT Vegetation Time series imagery," in Proceedings of the International Archives of the Photogrammetry, Remote Sensing and Spatial Information Sciences, pp. 915-920, Beijing, China, 2008.

[17] Z. Han, T. Wang, C. Yan et al., "Change trends for desertified lands in the Horqin Sandy Land at the beginning of the twentyfirst century," Environmental Earth Sciences, vol. 59, no. 8, pp. 1749-1757, 2010.

[18] H.-C. Duan, T. Wang, X. Xue, S.-L. Liu, and J. Guo, "Dynamics of aeolian desertification and its driving forces in the Horqin Sandy Land, Northern China," Environmental Monitoring and Assessment, vol. 186, no. 10, pp. 6083-6096, 2014.

[19] F. Shengyue and Z. Lihua, "Desertification control in China: possible solutions," Ambio: a journal of the Human Environment, vol. 30, no. 6, pp. 384-385, 2001.

[20] T. Wang, W. Wu, X. Xue, Z. Han, W. Zhang, and Q. Sun, "Spatialtemporal changes of Sandy desertified land during last 5 decades in Northern China," Acta Geographica Sinica, vol. 59, no. 2, pp. 203-212, 2004.

[21] X.-Y. Zhao, C.-M. Zhang, X.-A. Zuo et al., "Challenge to the desertification reversion in Horqin Sandy Land," Chinese Journal of Applied Ecology, vol. 20, no. 7, pp. 1559-1564, 2009.

[22] H.-L. Zhao, X.-Y. Zhao, R.-L. Zhou, T.-H. Zhang, and S. Drake, "Desertification processes due to heavy grazing in sandy rangeland, Inner Mongolia," Journal of Arid Environments, vol. 62, no. 2, pp. 309-319, 2005.

[23] X. Wang, F. Chen, and Z. Dong, "The relative role of climatic and human factors in desertification in semiarid China," Global Environmental Change, vol. 16, no. 1, pp. 48-57, 2006.

[24] J. Ellis, Grasslands and Grassland Sciences in Northern China, National Academies Press, Washington, DC, USA, 1992.

[25] W. Yan, New Paradigm of International Environmental Cooperation-Practice of Comprehensive Policy Studies in Desertification Countermeasure in China, Keio University Press, 2008 (Japanese).

[26] Wulantuya, "Land reclamation and land-use changes during last 50 years in Ke'erqin deserts, Inner Mongolia," Progress in Geography, vol. 19, no. 3, pp. 273-278, 2000 (Chinese).

[27] J. Paneque-Gálvez, J.-F. Mas, G. Moré et al., "Enhanced land use/cover classification of heterogeneous tropical landscapes using support vector machines and textural homogeneity," International Journal of Applied Earth Observation and Geoinformation, vol. 23, no. 1, pp. 372-383, 2013.

[28] M. F. Iqbal and I. A. Khan, "Spatiotemporal Land Use Land Cover change analysis and erosion risk mapping of Azad Jammu and Kashmir, Pakistan," Egyptian Journal of Remote Sensing and Space Science, vol. 17, no. 2, pp. 209-229, 2014.

[29] L. C. Alatorre and S. Beguería, "Identification of eroded areas using remote sensing in a badlands landscape on marls in the central Spanish Pyrenees," Catena, vol. 76, no. 3, pp. 182-190, 2009.

[30] R. C. Sharma, R. Tateishi, K. Hara, and K. Iizuka, "Production of the Japan 30-m land cover map of 2013-2015 using a random forests-based feature optimization approach," Remote Sensing, vol. 8 , no. 5, article no. 429, 2016.

[31] S. Brogaard and S. Prieler, "Land cover in the Horqin grasslands, North China. Detecting changes between 1975 and 1990 by means of remote sensing," IIASA Interim Report, International Institute for Applied System Analysis, Laxenburg, Austria, 1998, http://citeseerx.ist.psu.edu/viewdoc/download?doi= 10.1.1.41.6920\&rep $=$ rep1\&type $=$ pdf.

[32] S.-H. Ran and J.-J. Jin, "Evolvement and control of vulnerable ecological region-a case study in Ongniud Banner and Aohan Banner, Inner Mongolia," Chinese Geographical Science, vol. 14, no. 2, pp. 135-141, 2004.

[33] Q. L. Yan, J. J. Zhu, Z. B. Hu, and O. J. Sun, "Environmental impacts of the shelter forests in Horqin Sandy Land, Northeast China," Journal of Environmental Quality, vol. 40, no. 3, pp. 815824, 2011.

[34] S. Yan and Z. Liu, "Effects of dune stabilization on the plant diversity of interdune wetlands in northeastern Inner Mongolia, China," Land Degradation \& Development, vol. 21, no. 1, pp. 4047, 2010.

[35] J. A. Richards and X. Jia, Remote sensing digital image analysis, Springer, Berlin, Germany, 1999.

[36] T. Kavzoglu and P. M. Mather, "The use of backpropagating artificial neural networks in land cover classification," International Journal of Remote Sensing, vol. 24, no. 23, pp. 4907-4938, 2003.

[37] G. Mountrakis, J. Im, and C. Ogole, "Support vector machines in remote sensing: a review," ISPRS Journal of Photogrammetry and Remote Sensing, vol. 66, no. 3, pp. 247-259, 2011.

[38] P. Mantero, G. Moser, and S. B. Serpico, "Partially supervised classification of remote sensing images through SVMbased probability density estimation," IEEE Transactions on Geoscience and Remote Sensing, vol. 43, no. 3, pp. 559-570, 2005.

[39] C. Huang, L. S. Davis, and J. R. G. Townshend, "An assessment of support vector machines for land cover classification," International Journal of Remote Sensing, vol. 23, no. 4, pp. 725-749, 2002.

[40] T. Kavzoglu and I. Colkesen, "A kernel functions analysis for support vector machines for land cover classification," International Journal of Applied Earth Observation and Geoinformation, vol. 11, no. 5, pp. 352-359, 2009.

[41] Z. Kou, "Amelioration of desertification and construction of sustainable landuse system in Wulan-Aodu area," Towards Solving the Global Desertification Problem, vol. 4, pp. 45-47, 1994.

[42] Inner Mongolia Statistics Bureau, Inner Mongolia Statistical Yearbook, China Statistics Press, Beijing, China, 2015 (Chinese). 


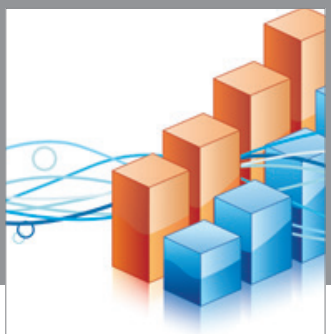

Advances in

Operations Research

vatem alat4

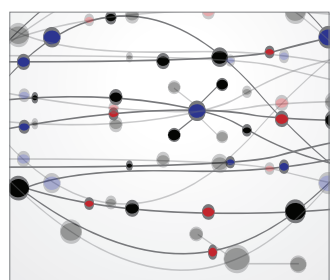

\section{The Scientific} World Journal
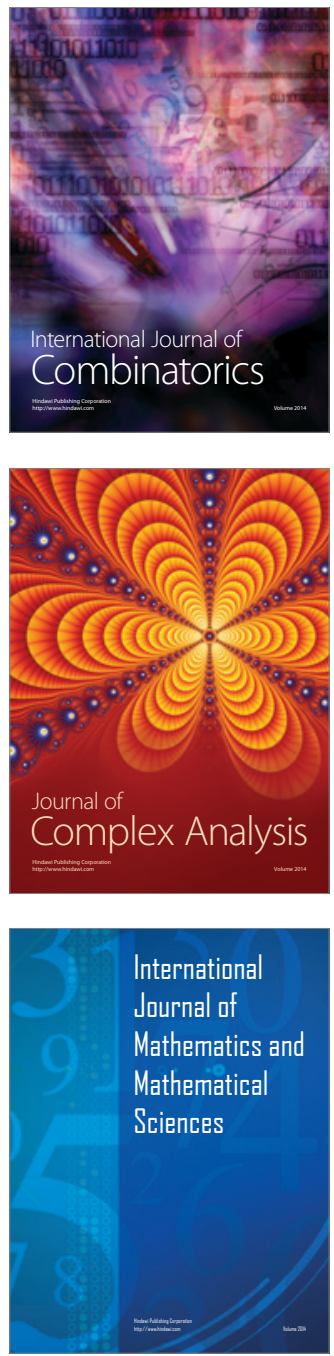
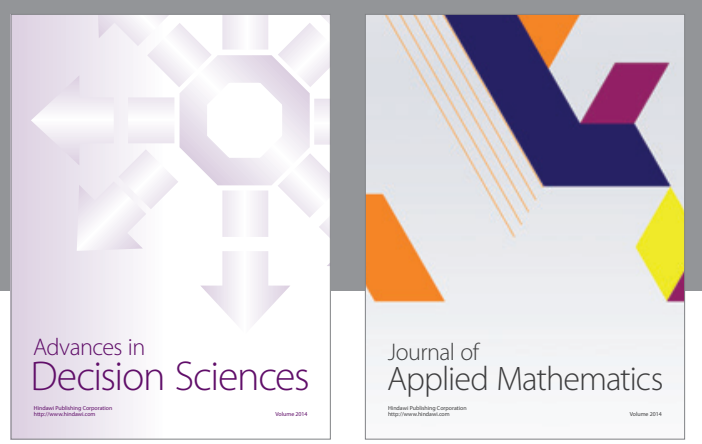

Algebra

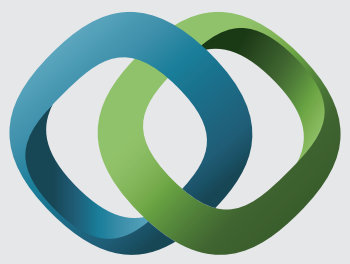

\section{Hindawi}

Submit your manuscripts at

https://www.hindawi.com
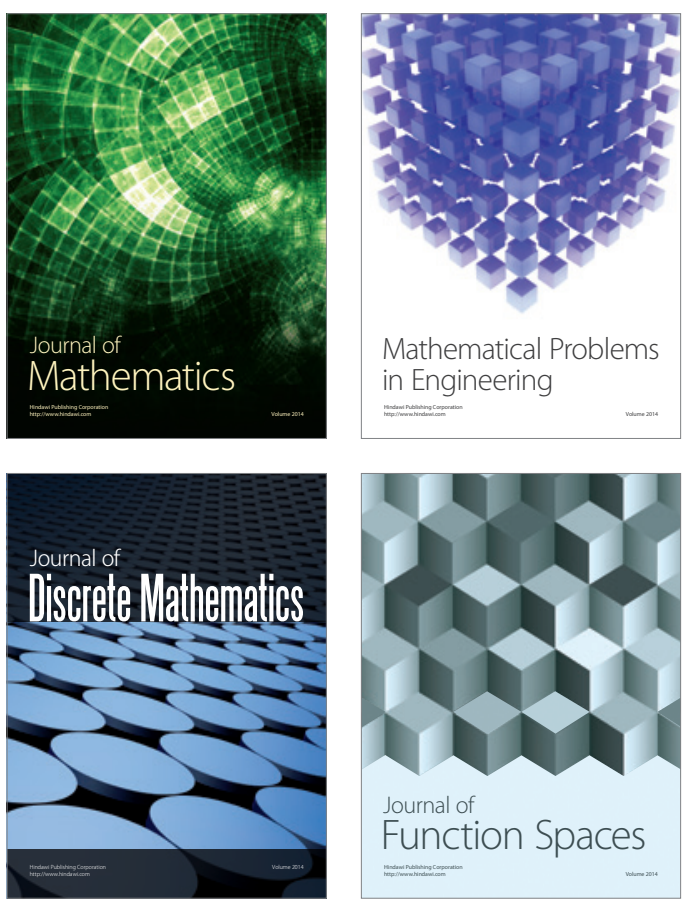

Mathematical Problems in Engineering
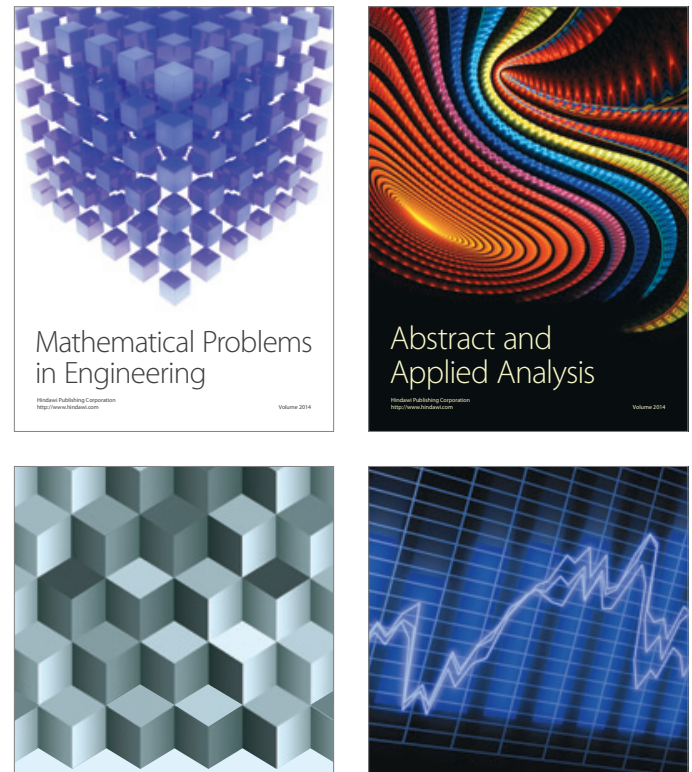

Journal of

Function Spaces

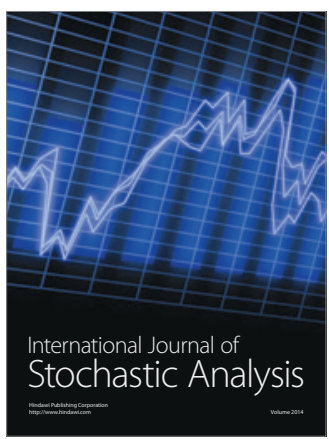

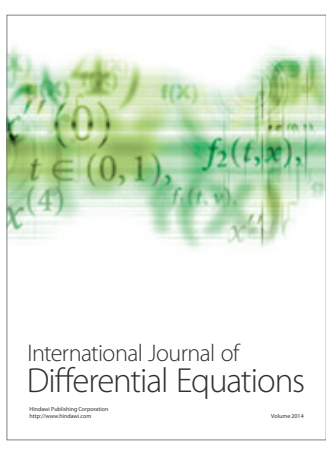
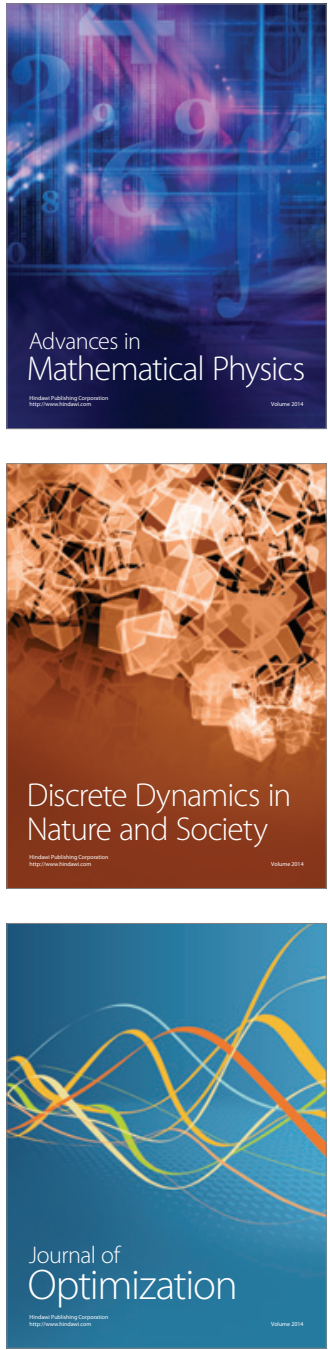